needs to be watchful of the risk of pneumothorax. The size of the lesion correlated with the development of pneumothorax with a smaller size associated with a higher risk.

\section{P41 INDWELLING PLEURAL CATHETER OR TALC PLEURODESIS: WHICH SHOULD WE FAVOUR?}

FL Sheel, S Akbar, HE Davies. University Hospital Llandough, Cardiff, UK

\subsection{6/thoraxjnl-2017-210983.183}

Introduction Malignant pleural effusions (MPE) cause disabling symptoms often relieved by thoracentesis. Indwelling pleural catheter (IPC) insertion and talc pleurodesis (TP) are equally effective treatments ${ }^{1}$ yet; current BTS guidelines suggest talc pleurodesis as the preferred method of fluid control ${ }^{2}$ IPCs may reduce hospital bed-days and minimise the need for repeated pleural intervention. ${ }^{3}$

Aim To compare the impact of IPC and TP on length of hospital stay (LOS) and need subsequent pleural intervention. Complication frequency and survival rates were also measured. Methods Retrospective review of Pleural clinic and electronic case note records of all MPE patients at our institution requiring TP or IPC insertion over an 18 month period (01/05/15$01 / 11 / 16)$.

Results A total of 73 procedures (46 TP, 27 IPCs) were carried out on 71 patients. Mean LOS was shorter in the IPC group (0.85 (0-7) days) than with TP (7.65 (2-36) days). 11 patients (24\%) required further pleural intervention following TP ( 2 had repeat TP, 8 had an IPC and one patient underwent therapeutic pleural aspiration). One patient in the IPC group had a second procedure (2nd IPC placed - a patient with cognitive impairment cut his tube). There were no hospitalisations as a consequence of complications in the IPC patients; 2 patients required antibiotics for drain site cellulitis (7\%). In the TP group, 3 drains fell out (7\%); one patient had a pneumothorax. 52 patients $(73 \%)$ had died at follow-up (until January 2017). Median (IQR) survival after IPC insertion was 62 (24-146) compared with 74 (23-153) days.

Conclusions Our findings support first-line use of IPC in patients with a symptomatic MPE. IPCs resulted in shorter LOS and reduced the need for subsequent ipsilateral pleural drainage. All patients necessitating definitive intervention for a symptomatic MPE should be offered the choice between IPC and TP.

\section{P42 ESTABLISHING AN INDWELLING PLEURAL CATHETER SERVICE FOR AMBULATORY MANAGEMENT OF SYMPTOMATIC MALIGNANT PLEURAL EFFUSION}

M Parsonage, NJ Stevenson, CA Paxton. Wirral University Teaching Hospital NHS Foundation Trust, Merseyside, UK

\subsection{6/thoraxjnl-2017-210983.184}

Introduction and Objectives We introduced our Indwelling Pleural Catheter (IPC) Service in 2015 to allow ambulatory management of patients with malignant pleural effusions (MPE). Our aim was to review data to establish our patient group, prognostic indicators, rate of autopleurodesis, complications and length of stay (LOS).

Methods Data was collected from Trust electronic records for patients who had IPC placement for MPE June 2015 - July 2017. In addition to patient demographics and outcomes, LENT prognostic score ${ }^{1}$ (pleural fluid lactate dehydrogenase, Eastern Cooperative Oncology Group (ECOG) performance status (PS), neutrophil-to-lymphocyte ratio and tumour type), complications and LOS were analysed.

Results 54 patients had IPC placement, 32 (59\%) female. Median age was 71 years (24-92). IPC placement by tumour type based on histopathology: mesothelioma 7 (13\%), lung 17 (32\%), haematological $1(2 \%)$, breast $12(22 \%)$, gynaecological 5 (9\%), renal 1 (2\%), other tumour types 11 (20\%). Median ECOG PS 3. 59\% patients died with median survival of 44 days (4-257). Death by tumour type: mesothelioma 6 (19\%), lung $11(34 \%)$, haematological $1(3 \%)$, breast 5 (16\%), gynaecological 2 (6\%), renal 1 (3\%), other tumour types $6(19 \%)$. No recorded complications at insertion. Late infection rate 4/ $54(7.4 \%)$. IPC removal for autopleurodesis 7/54 (13\%), with timing of autopleurodesis occurring at 4-8 weeks 1 (14\%), 812 weeks 3 (43\%), $\geq 12$ weeks 3 (43\%). Median LOS $=1$ day. Patients reported a high degree of satisfaction with the service.

Conclusions Our IPC service has helped us offer a patient focused choice through the use of a validated prognostication tool. We have demonstrated that it is safe and effective, and supports admission avoidance. We believe an IPC service promotes cost and clinical effectiveness, through a more modern approach when managing patients with MPE.

\section{REFERENCES}

1. Clive AO, Kahan BC, Hooper CE et-al. Predicting survival in malignant pleura effusion: Development and validation of the LENT prognostic score. Thorax 2014 doi:10.1136/thoraxjnl-2014-205285

\title{
REFERENCES
}

1. Davies, et al. JAMA 2012:307(22):2383-9.

2. BTS Pleural Diseases Guidelines 2010.

3. Fysh, et al. BMJ Open 2014;4(11).

\begin{tabular}{|c|c|c|c|c|c|c|c|}
\hline $\begin{array}{l}\text { Combined LENT } \\
\text { Score }\end{array}$ & Mesothelioma & Lung & Haematological & Breast & Gynaecological & Renal & Other \\
\hline $\begin{array}{l}\text { Low } 319 \text { risk days } \\
(0 \%)\end{array}$ & $0(0 \%)$ & $0(0 \%)$ & $0(0 \%)$ & $0(0 \%)$ & $0(0 \%)$ & $0(0 \%)$ & $0(0 \%)$ \\
\hline $\begin{array}{l}\text { Med risk } \\
130 \text { days }(57 \%)\end{array}$ & $7(23 \%)$ & $3(10 \%)$ & $0(0 \%)$ & $\begin{array}{l}11 \\
(35 \%)\end{array}$ & $5(10 \%)$ & $0(0 \%)$ & $5(16 \%)$ \\
\hline $\begin{array}{l}\text { High risk } 44 \text { days } \\
(43 \%)\end{array}$ & $0(0 \%)$ & $\begin{array}{l}14 \\
(61 \%)\end{array}$ & $1(4.5 \%)$ & $\begin{array}{l}1 \\
(4.5 \%)\end{array}$ & $0(0 \%)$ & $\begin{array}{l}1 \\
(4.5 \%)\end{array}$ & $6(26 \%)$ \\
\hline
\end{tabular}

